12. Xu-Guang An, Y. Liu, Jin-Wen Ye, Lin-Zhi Wang, PengYue Wang. Grain refining efficiency of SHS Al $-\mathrm{Ti}-\mathrm{B}-\mathrm{C}$ master alloy for pure aluminum and its effect on mechanical properties. Acta Metallurgica Sinica (English Letters). 2016. Vol. 29, Iss. 8. pp. 742-747.

13. Rakhmonov J., Timelli G., Bonollo F. The influence of AlTi5B1 grain refinement and the cooling rate on the formation behaviour of $\mathrm{Fe}$-rich compounds in secondary $\mathrm{AlSi}_{8} \mathrm{Cu}_{3}$ alloys. Metallurgia Italiana. 2016. Vol. 108 (6). pp. 109-112.

14. Wang X., Han Q. Grain refinement mechanism of aluminum by $\mathrm{AI}-\mathrm{Ti}$ - B master alloys, in Light Metals 2016 (ed. E. Williams). John Wiley \& Sons, Inc., Hoboken, NJ, USA. 2016.
15. Zhang Z., Wang J., Xia X., Zhao W., Liao B., Hur B. The microstructure and compressive properties of aluminum alloy (A356) foams with different $\mathrm{Al}-\mathrm{Ti}-\mathrm{B}$ additions. Medziagotyra. 2016. Vol. 22, Iss. 3. pp. 337-342.

16. Wang X., Han Q. Grain refinement mechanism of aluminum by $\mathrm{Al}$ - Ti - B master alloys. TMS Light Metals, 2016. pp. 189-193.

17. Baranov V. N., Sidelnikov S. B., Bezrukikh A. I., Zenkin E. Y., Research of rolling regimes and mechanical properties of cold-rolled, annealed and welded semi-finished products from experimental alloys of $\mathrm{Al}-\mathrm{Mg}$ system, economically alloyed by scandium. Tsvetnye Metally. 2017. No. 9. pp. 83-88.

\title{
3D modelling of the large-capacity ingots of an Al - Mg system aluminium alloy doped with scandium rolling process
}

UDC 621.777

\author{
I. N. Dovzhenko, Assistant Professor, Chair of Metal Forming ${ }^{1}$ \\ N. N. Dovzhenko, Professor, Chair of Metal Forming ${ }^{1}$ \\ S. B. Sidelnikov, Professor, Head of the Chair of Metal Forming ${ }^{1}$, e-mail: sbs270359@yandex.ru \\ I. L. Konstantinov, Assistant Professor, Chair of Metal Forming ${ }^{1}$ \\ ${ }^{1}$ Siberian Federal University, Krasnoyarsk, Russia.
}

\begin{abstract}
Implemented has been analysis of strain-stress and temperature states during hot rolling process for ingots of an $\mathrm{Al}$ - Mg system aluminium alloy doped with scandium. It has been shown that in case of hot rolling of the large-capacity ingots without using vertical (edger) stands under nonuniform deformation conditions, changes of breakdown bar geometry take place, especially on the first rolling passes. This nonuniformity of a metal flow is caused by intensive deformation of the ingot's outer layer and insignificant metal deformation in the central area, which result in formation of concave edges with a convex near-edge region at front end of the ingot. Metal failure in different zones of the billet may be also caused by casting defects, since essentially nonuniform deformation and stress distribution over thickness as well as that of temperature is typical for hot rolling process, especially during first passes. The metal temperature calculation has shown that sequential deformation is favourable to gradual temperature increase about $5-10^{\circ} \mathrm{C}$ by pass, but heat abstraction from the central part of an ingot rises as the billet thickness is decreasing and time of pauses between passes is increasing. At the same time, the edges of a strained half-finished product are the very cold areas. A breakdown bar temperature essentially differs over both surface and volume (up to $10-12^{\circ} \mathrm{C}$ ), especially at first passes, and on further rolling, their difference is increasing when temperature on the surface and in the center rise and amount to $25-30^{\circ} \mathrm{C}$ in comparison with the edge temperature. Based on the Cockroft-Latham criterion, ascertained are the breakdown bar areas with the greatest probability of crack propagation, which is confirmed by results of experimental investigation in an industrial environment. Analysis of changes of the CockroftLatham criterion values through passes has demonstrated that values of this criterion at the breakdown bar edge exceed critical value of 1 in pass No. 15 at total deformation of $68.3 \%$.
\end{abstract}

Key words: hot rolling, large-capacity ingots, scandium, strain-stress state, temperature, CockroftLatham failure criterion.

DOI: $10.17580 /$ nfm.2017.02.11

\section{Introduction}

$\mathrm{R}$ ecently, aluminium alloys doped with rareearth and transition metals are being increasingly commercialized [1]. One of the ways of their application in aircraft, shipbuilding and motor-car industries is manufacturing plates and sheets of scandium-doped $\mathrm{Al}-\mathrm{Mg}$ system alloys. Topicality of producing such alloys and developing technologies for their processing is emphasized by implementation of the present work in accordance with the project 03.G25.31.0265 "Development of sparingly alloyed high-strength $\mathrm{Al}-$ Sc alloys for application in motor vehicle transport and shipping industry" in the framework of the Program on realization of complex projects in high-tech production organization approved by the resolution of the Government of the Russian Federation No. 218 dated April 9, 2010. 
Hot-rolled plates and sheets of these alloys are produced by hot rolling of flat large-capacity ingots (slabs), and cold-rolled sheets, strips and bands are manufactured by consequent cold rolling. An essential part of metal losses on hot-rolling mills is connected with the intermediate and finished steel defeating by surface cracks, being predominantly situated in a near-edge zone of a billet. Presence of such defects leads to increased amount of rejected metal, higher expenditure coefficients, grow of the production prime cost and lowering of its competitiveness.

At present, there is no consensus of opinion regarding the reasons of near-edge cracks formation. Some researchers believe that defects of this kind appear in the process of ingot crystallization during continuous casting and are inherited for rolling forming. There also exists an opinion [2] that the near-edge cracks formation takes place in hot-rolling process directly, obviously by reason of irregular flow of metal, which is conditioned by unevenness of the deformation temperature, degree and velocity distribution over breakdown bar section.

In order to determine the reasons of appearing defects of this kind in the slab hot rolling process, mathematical modelling with the use of different software packages is employed for aluminium alloys [3-6], as well as for the other ones [7-12].

Thus the paper is aimed at investigating the hot rolling process of an $\mathrm{Al}-\mathrm{Mg}$ system aluminum alloy doped with scandium with the aid of computer simulation through applying the DEFORM-3D software. In that context, analysis of changes of breakdown bar geometry, study of temperature conditions and strain-stress state of metal, and estimation of reasons of the rolled metal failure in a near-edge area should be fulfilled.

\section{Research procedure}

To work out a model for the hot rolling process on an industrial reversing mill, the data have been used as follows:

- diameter of the working rolls of $700 \mathrm{~mm}$;

- width of the body of roll of $2800 \mathrm{~mm}$;

- an initial ingot temperature equal to $425^{\circ} \mathrm{C}$;

- velocity of $1.5 \mathrm{~m} / \mathrm{s}$ during first passes wit consequent increase up to $5 \mathrm{~m} / \mathrm{s}$;

- dimensions of an original ingot were $300 \times 1400 \times$ $\times 1700 \mathrm{~mm}$;

- hot rolling up to dimensions of $80 \times 1500 \times \mathrm{L} \mathrm{mm}$;

- the roller model - absolutely rigid;

- technological pauses between passes from 10 to $30 \mathrm{~s}$;

- number of finite elements to which the original ingot has been broken has amountedw to 100 thousand pieces; as height of breakdown bar decreases and its length grows, their number has been brought to 180 thousand pieces.

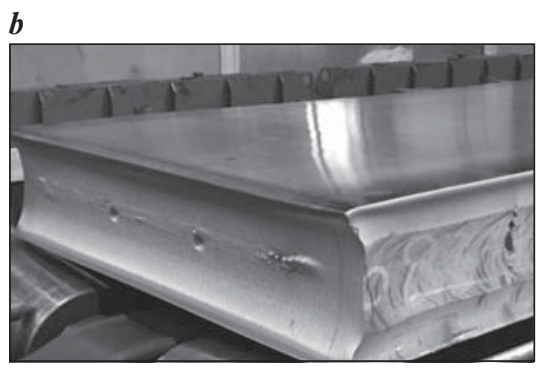

A scandium-doped $\mathrm{Al}$ - Mg system alloy with the properties close to that of an alloy 01570 has been taken as a material.

The hot rolling process modelling has been carried out for $1 / 4$ of a blank without application of an edger (vertical) stand, therefore the symmetrical views have been added to the DEFORM-3D software.

The rolling process model, used for computations in the DEFORM-3D software is represented in Fig. 1, $a$. With respect to rolling speed, it should be noted that it is not advisable to apply rolling speed higher than $1.0-1.2 \mathrm{~m} / \mathrm{s}$ in first passes, especially in case of heavy reductions, since considerable part of external surface of a band may become covered by cracks in consequence of intensive sticking.

With further rolling, the reduction value is limited only by angle of bite and by magnitude of forces appearing in the rolling process. Therefore, reductions are usually distributed over passes in such a way that in the beginning of the rolling process they are equal to $8-10 \%$, and then, as the cast structure is breaking and plasticity of breakdown bar is rising, they enlarge achieving $45 \%$ and more in last passes.

Number of hot rolling passes and drafting pattern for obtaining the slab of a finished size are listed in the Table.

\begin{tabular}{|c|c|c|c|c|}
\hline $\begin{array}{c}\text { Pass } \\
\text { number }\end{array}$ & Thickness, mm & $\begin{array}{l}\text { Reduction in } \\
\text { thickness, } \mathrm{mm}\end{array}$ & $\begin{array}{c}\text { Unit } \\
\text { reduction, \% }\end{array}$ & $\begin{array}{l}\text { Pause } \\
\text { time, s }\end{array}$ \\
\hline 0 & 300 & - & - & - \\
\hline 1 & 290 & 10 & 3 & 10 \\
\hline 2 & 280 & 10 & 3 & 10 \\
\hline 3 & 270 & 10 & 4 & 10 \\
\hline 4 & 260 & 10 & 4 & 10 \\
\hline 5 & 245 & 15 & 6 & 10 \\
\hline 6 & 230 & 15 & 6 & 10 \\
\hline 7 & 215 & 15 & 7 & 10 \\
\hline 8 & 200 & 15 & 7 & 10 \\
\hline 9 & 185 & 15 & 8 & 10 \\
\hline 10 & 170 & 15 & 8 & 30 \\
\hline 11 & 155 & 15 & 9 & 30 \\
\hline 12 & 140 & 15 & 10 & 30 \\
\hline 13 & 125 & 15 & 11 & 30 \\
\hline 14 & 110 & 15 & 12 & 30 \\
\hline 15 & 95 & 15 & 14 & 30 \\
\hline 16 & 80 & 15 & 16 & 30 \\
\hline
\end{tabular}


In the present work, there has been carried out an analysis of 16 rolling passes up to breakdown bar thickness of 80 $\mathrm{mm}$ in the context of the strain-stress state estimation, changing breakdown bar geometry without rolling in edger stand, temperature over the billet volume and the Cockroft-Latham failure criterion values [13-17].

\section{Results and discussion}

When modelling hot rolling process of large-capacity ingots, observed is a change of breakdown bar geometry, typical for metal rolling in an industrial and laboratory environment at the same operating modes (Fig. 1, b) [18]. More intensive deformation of surface layers as compared with the central ones leads to different outflow rates of metal layers and appearance of tensile stresses.

Temperature distribution over breakdown bar surface is quite irregular, since temperature of side surface and edge zone is lower than that of the breakdown bar surface (Fig. 2). Analysis of the temperature distribution over breakdown bar volume has shown that the surface layers are warmed up to higher temperatures due to more intensive deformation. Besides, central layers of largecapacity ingots in the first passes of deformation process practically don't get warm. As the breakdown bar thickness diminishes, temperature over section becomes even.

Temperature of the central part of breakdown bar has minimal heat elimination, and sequential deformation is favourable to gradual temperature increase about $5-10{ }^{\circ} \mathrm{C}$ by pass, but heat abstraction from the central part of an ingot rises as metal thickness is decreasing and time of pauses

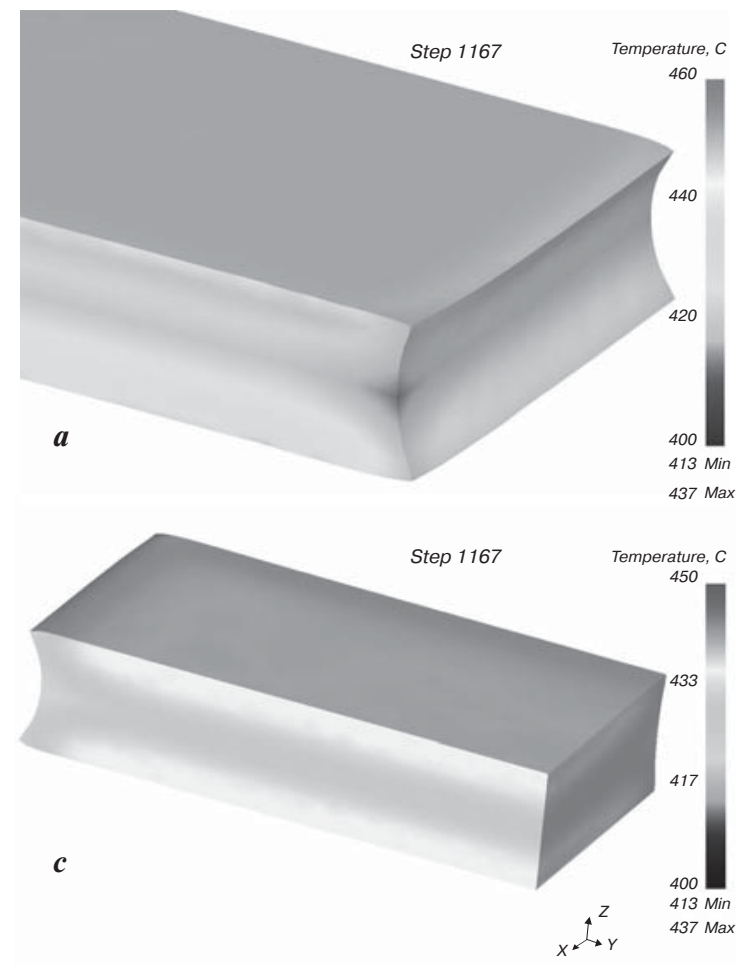

between passes extends up to $30 \mathrm{~s}$. Thus analysis of the strip temperature fileds distribution through the rolling process has revealed that breakdown bar edges are the very cold areas.

The metal deformation in different layers over breakdown bar thickness up to the 10-th pass with time of a pause between passes equal to $10 \mathrm{~s}$ leads to temperature rise from 425 to $460{ }^{\circ} \mathrm{C}$; it is more intensive on the surface and in the center of the breakdown bar and less intensive in its edge. After that pass, the pause time has been enlarged up to $30 \mathrm{~s}$ for the avoidance of the breakdown bar overheating, as a result of which its temperature has stabilized and temperature of the edge area has lowered to $423^{\circ} \mathrm{C}$.

The temperature distribution in breakdown bar volume correlates with the accumulated strain rate distribution over breakdown bar longitudinal section and cross-section after passes (Fig. 3, $a, b$ ).

Minimal deformation is accumulated in a middle of the billet and is increasing until maximum value on a surface of the billet. One can see that after pass No. 4 deformation is localized in a near-surface layers and doesn't spread until breakdown bar center. As metal thickness lessens up to $80 \mathrm{~mm}$ at pass No. 16, deformation extends over whole thickness of breakdown bar.

The indicated pattern of breakdown bar deformation throughout passes confirms distribution of stress intensity in a deformation zone over breakdown bar longitudinal section through passes (Fig. 3, $c, d$ ). If one examines stress distribution along the $Y$ axis in a deformation zone through passes, it is possible to reveal an existence of tensile stress in the metal on breakdown bar surface in zones in front of the point of entry to a deformation zone and the point of
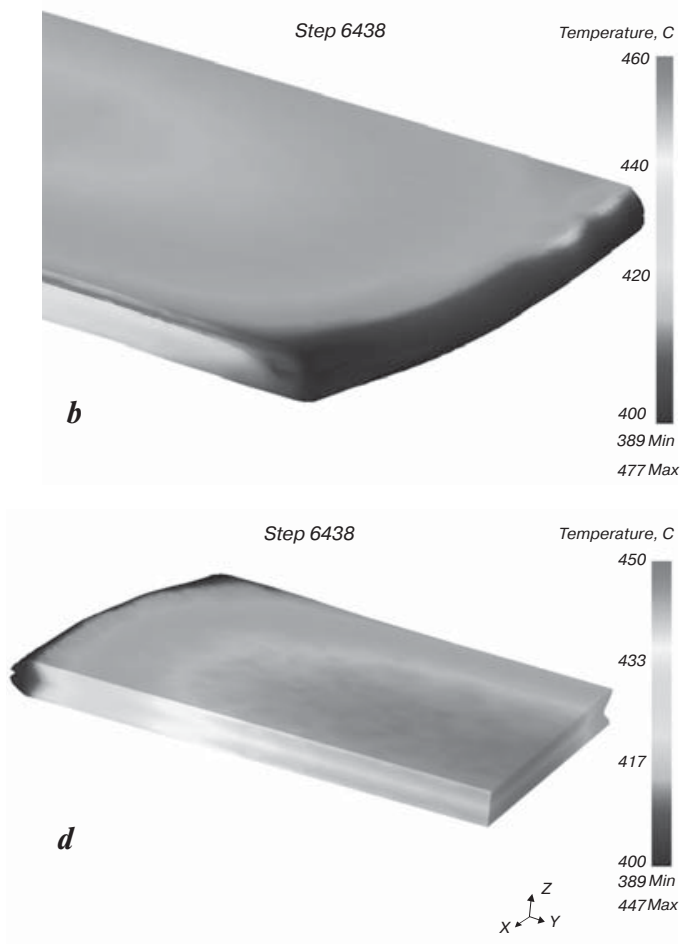

Fig. 2. Temperature distribution over breakdown bar surface $(a, b)$ and temperature distribution over breakdown bar section $(c, d)$ after passes: $a, c-$ No. $4 ; b, d-$ No. 16 

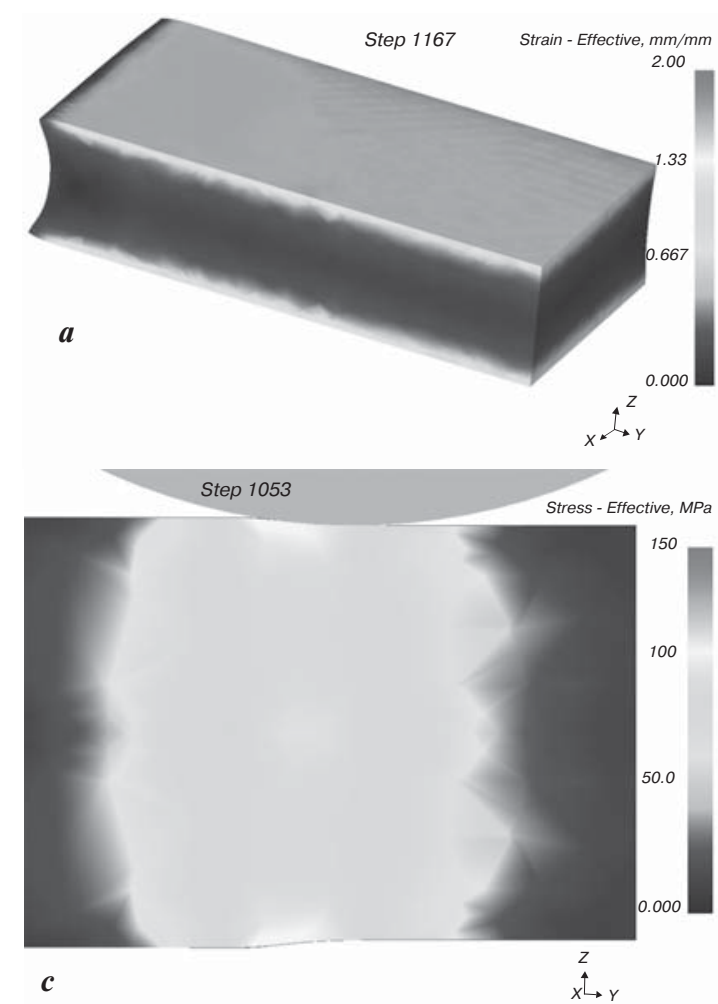
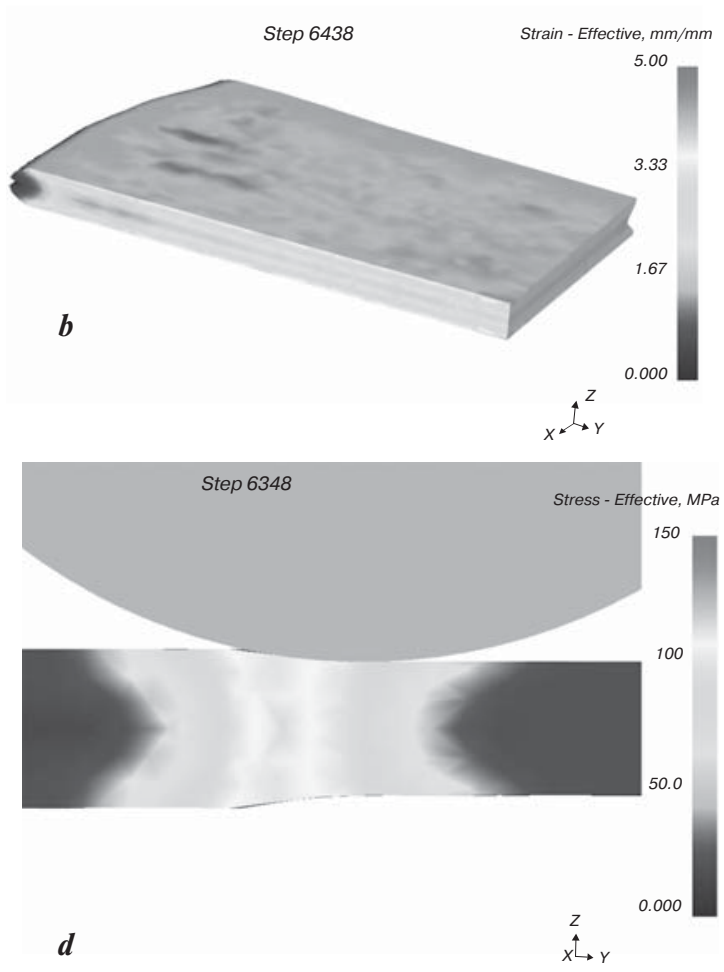

Fig. 3. The accumulated strain rate distribution over breakdown bar longitudinal section and cross-section $(a, b)$ and stress intensity distribution in deformation zone over breakdown bar longitudinal section $(c, d)$ after passes: $a, c-$ No. $4 ; b, d-$ No. 16

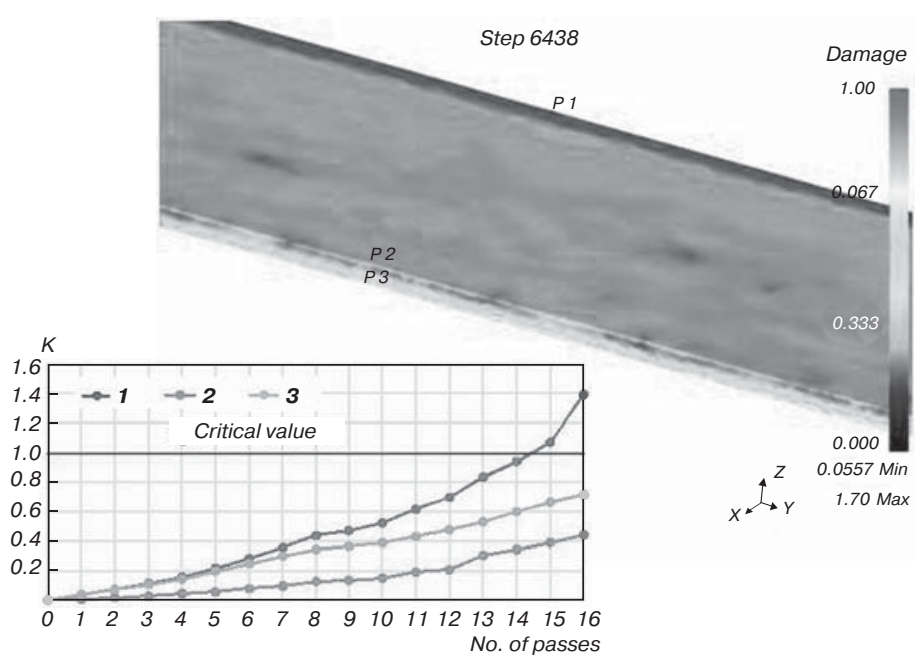

Fig. 4. The Cockroft-Latham criterion values change by pass at three points of the central part of breakdown bar: P3 - center of breakdown bar, P2 - surface in the middle and P1 - an edge (shown is $1 / 4$ of a blank):

1 - edge; $2-$ middle of the surface; $3-$ centre

way out of it as well as in the center and on the side verges of breakdown bar, especially during first passes.

Fig. 4 illustrates changes of the Cockroft-Latham criterion values $(\mathrm{K})$ through passes at three points of the central part of breakdown bar length: center over breakdown bar thickness, surface in the middle and an edge (angle of transition from the surface to an edge verge). As may be seen, the Cockroft-Latham criterion values at the breakdown bar edge are approaching to the critical value of that criterion the most rapidly; at pass No. 15 they exceed 1.
Analysis of the Cockroft-Latham criterion distribution over breakdown bar surface allows one to draw a conclusion that after pass No. 8 it approaches to 0.5 on the edge of breakdown bar, which indicates unfavourable scheme of strained mode in this area and possibility of appearance and further growth of transverse crotchcorner cracks of breakdown bar during subsequent rolling. After pass No. 14, the Cockroft-Latham criterion value in the center of breakdown bar is close to 0.7 , tends to critical value at the edge and on the pass No. 15 exceeds 1 , which indicates that microcracks may appear and then progress. After pass No. 16 the breakdown bar edge is capable to become covered by cracks, since the Cockroft-Latham criterion value exceeds 1 , which is also testified by results of industrial research (Fig. 1,b).

As may be seen from the adduced data, an irregular temperature distribution and consequently deformation and stress distribution over breakdown bar volume and especially in the edge area, make a significant impact upon probability of cracks appearance, in the near-edge zone in the first place.

\section{Conclusions}

1. In the hot rolling process of large-capacity billets without using vertical (edger) stands under essentially nonuniform deformation conditions, changes of breakdown bar geometry take place, which are caused by very intensive deformations of the outer layers of an ingot on the first rolling passes, while the central ones remain practically undistorted, which result in formation of 
concave edges with a convex near-edge region at front end of the ingot and considerable tensile stresses appear.

2. The most dangerous zones of possible crack and destruction propagation are situated in the near-edge zones of concave edge, as well as in central bulks of metal, where tensile stresses are concentrated.

3. On the base of a computer model of hot rolling process designed in the DEFORM-3D software, there has been implemented an analysis of processing the largecapacity ingots of an $\mathrm{Al}-\mathrm{Mg}$ system alloy doped with scandium in an industrial environment, which has allowed one to ascertain that:

- when rolling the ingot with thickness of $300 \mathrm{~mm}$ with single reductions of 3-4\% during first passes, minimal accumulated equivalent deformation is forming in the center over equivalent thickness, and it is a maximum on its surface;

- as number of passes and reductions for a pass increase, difference in accumulated equivalent deformation between the surface and central layers lessens, but still remains considerable up to the breakdown bar thickness of $80 \mathrm{~mm}$, at the same time deformation extends over whole thickness of breakdown bar;

- temperature of breakdown bar, especially during first passes, significally differs both over the surface and over volume: although in the center and at the edges temperature is $425^{\circ} \mathrm{C}$, it achieve $437^{\circ} \mathrm{C}$ on the surface and the layers adjacent to it; during further rolling, difference of these temperatures is $25-30{ }^{\circ} \mathrm{C}$, tough temperatures on the surface and in the center are rising;

- after the 10-th pass, the pause time should be enlarged up to $30 \mathrm{~s}$ for the avoidance of breakdown bar overheating, at the same time the edge zone temperature will amount to $423^{\circ} \mathrm{C}$, as a result of which the metal temperature will stabilize;

- the breakdown bar thermal state may be controlled by changing time of pauses between passes or by using an additional cold introducing onto breakdown bar surface, increasing thereby the rolling efficiency on single reductions without cracks formation;

- it is shown that the Cockroft-Latham criterion values at the breakdown bar edge are approaching to the critical value of that criterion the most rapidly; at pass No. 15 they exceed 1 at total deformation of $68.3 \%$;

- it is possible to eliminate an edge presence on concave edges and to increase plasticity resources of the breakdown bar by applying vertical (edger) stands.

\section{References}

1. Gorbunov Yu. A. The Role and Prospects of Rare Earth Metals in the Development of Physical-Mechanical Characteristics and Applications of Deformable Aluminum Alloys. Zhurnal Sibirskogo federalnogo universiteta. Seriya: Tekhnika i tekhnologii. 2015. Vol. 8, No. 5. pp. $636-645$.

2. Matveev M. A. Numerical estimation of the probability of metal failure under hot plastic deformation by means of the Cockcroft-Latham criterion. Journal of engineering sciences and technology. 2017. Vol. 23 (02). pp. 109-126.
3. Inoue T. Strain variations on rolling condition in accumulative roll-bonding by finite element analysis. International conference. Japan, 2005. pp. 358-365.

4. Roumina R., Sinclair C. W. Deformation geometry and through-thickness strain gradients in asymmetric rolling. Metallurgical and Materials Transactions. 2008. No. 5. pp. 3-10.

5. Hassan A. K. F., Khalaf H. I. Three dimensional finite element simulation of Cold flat rolling. Al-Qadisiya Journal for Engineering Sciences. 2011. No. 1. pp. 502-515.

6. Shahani A. R., Nodamaie S. A., Slehinia I. Parametric study of hot rolling process by the finite element method. Mechanical Engineering. Vol. 16, No. 2. pp. 130-139.

7. S. V. Ershov et al. Role of theoretical solving of plastic deformation tasks in definition of shear strain by hot-rolled breakdown section during the high bars rolling. Metallurgicheskaya i gornorudnaya promyshlennost. 2009. No. 3. pp. 41-43.

8. Ershov S. V., Levchenko G. V., Golovko D. S. Theoretic definition of the type of distribution of shear strain by hot-rolled breakdown section during the high bars rolling. Derzhavniy vishchiy navchalniy zaklad "Donetskiy natsionalniy tekhnichniy universitet". Naukovi pratsi. "Metalurgiya". 2008. No. 10. pp. 93-98.

9. Salganik V. M. et al. Structure formation modeling of low-alloyed steel during thick roughing-down. Stal. 2011. No. 2. pp. $40-44$.

10. Shmakov A. V. et al. Complex modeling of controlled rolling technology for high-strength microalloyed pipe steels on plate mill 5000. Stal. 2012. No. 2. pp. 42-46.

11. Kawalla R., Schmidtchen M. Numerical simulation of hot rolling. Materials Science Forum. 2013. Vol. 762. pp. 22-30.

12. Dovzhenko N. N., Dovzhenko I. N., Sidelnikov S. B. 3D modeling of large steel-copper billet rolling for electrolyzer cathode rods. Tsvetnye Metally. 2016. No. 12. pp. 74-78.

13. Cockcroft M. G., Latham D. J. Ductility and the Workability of Metals. Journal of the Institute of Metals. 1968. Vol. 96. pp. 33-39.

14. Botkin A. V., Valiev R. Z., Stepin P. S., Baymukhametov A. Kh. Assessment of damaged metal during the cold plastic deformation using Cockcroft-Latam failure model. Deformatsiya $i$ razrushenie materialov. 2011. No. 7. pp. 17-22.

15. Matveev M. A. Physical-mathematical analysis of the reasons of near-rim fissures formation in hot-rolled sheets made of pipe steels: Dissertation ... of Candidate of Engineering Sciences. Saint Petersburg : Sankt-Peterburgskiy gosudarstvennyy politekhnischeskiy universitet. 2015. $202 \mathrm{p}$.

16. Kolbasnikov N. G., Matveev M. A., Zotov O. G., Glukhov P. A., Korchagin A. M. Investigation of reasons of surface fissures formation during thick sheets rolling and microalloyed steel pipes manufacturing. Peculiarities of rolling in two-phase area. Stal. 2016. No. 7. pp. 34-40.

17. Kolbasnikov N. G., Mishin V. V., Shishov I. A., Kistankin I. S., Zabrodin A. V. Development of non-destructive modes of warm rolling of nanocrystalline berillium by mathematical modeling methods. Deformatsiya i razrushenie materialov. 2013. No. 9. pp. 14-24.

18. Baranov V. N., Sidelnikov S. B., Bezrukikh A. I., Zenkin E. Yu. Research of rolling regimes and mechanical properties of cold-rolled, annealed and welded semi-finished products from experimental alloys of $\mathrm{Al}-\mathrm{Mg}$ system, economically alloyed by scandium. Tsvetnye Metally. 2017. No. 9. pp. 83-88. 